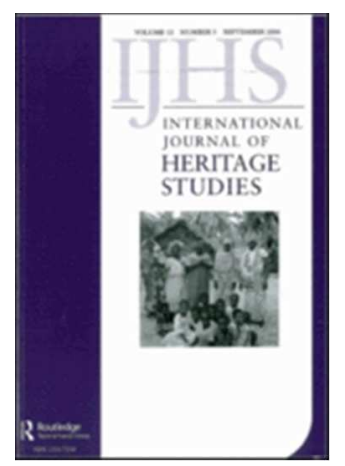

Alternative Radio: Exhibiting radio and music heritage after the Christchurch earthquakes

\begin{tabular}{|r|l|}
\hline Journal: & International Journal of Heritage Studies \\
\hline Manuscript ID & RJHS-2016-0351.R1 \\
\hline Manuscript Type: & Original Article \\
\hline Keywords: & Earthquake, Alternative radio, RDU, Christchurch, museum \\
\hline \multicolumn{2}{|l}{} \\
\hline
\end{tabular}

SCHOLARONE ${ }^{m}$

Manuscripts 


\title{
Alternative Radio: Exhibiting radio and music heritage after the Christchurch earthquakes
}

\begin{abstract}
This article examines the representation of Christchurch, New Zealand, student radio station RDU in the exhibition Alternative Radio at the Canterbury Museum in 2016. With the intention of 'making visible what is invisible' about radio broadcasting, the exhibition articulated RDU as a point of interconnection between the technical elements of broadcasting, the social and musical culture of station staff and volunteers, and the broader local and national music scenes. This paper is grounded in observations of the exhibitions and associated public programmes, and interviews with the key participants in the exhibition including the museum's exhibition designer and staff from RDU, who acted as independent practitioners in collaboration with the museum. Alternative Radio also addressed the aftermath of the major earthquake of 22 February 2011, when RDU moved into a customised horse truck after losing its broadcast studio. The exhibition came about because of the cultural resonance of the post-quake story, but also emphasised the long history of the station before that event, and located this small student radio station in the broader heritage discourse of the Canterbury museum, activating the historical, cultural, and personal memories of the station's participants and audiences.
\end{abstract}

Keywords: earthquake; memory; student radio; RDU; New Zealand; Christchurch

\section{Alternative Radio}

In 2016 the Canterbury Museum in Christchurch New Zealand hosted an exhibition focused on the fortieth anniversary of the local student radio station, RDU. Alternative Radio told the story of the station's establishment and accomplishments and traced RDU's role in the Christchurch music scene. Like any historical survey in Christchurch after 2011 it also addressed the aftermath of the earthquakes that began in September 2010, and particularly the major quake of 22 February 2011. RDU's post-quake move into a customised horse truck 
epitomised the discourse of resilience applied to Christchurch in the years after the earthquakes (Joyce 2015). The exhibition came about because of the cultural resonance of the post-quake story, but it also emphasised the long history of the station before that event, articulating the objects, music, and practices of 'alternative' radio within the broader cultural heritage of the city.

RDU started broadcasting as Radio U, the University of Canterbury Students' Association (UCSA) radio club, using a temporary license to cover the University's Orientation week in 1976. The broadcasters were inspired by College radio in the US - the letter of application for the Radio U 1978 license advised that the station had become a member of the "Intercollegiate Broadcasting System of America", the handbook of which provided information and assistance in running a university radio station (Wyse, 1977). Radio stations were started at other New Zealand universities in the following years, which coincided with the emergence of punk music and local bands inspired by it, including those associated with the Flying Nun record label (Churton 2003, RNZ 2015, Casserley 2015, Shepherd 2016). The 'DIY' ethos was a cultural marker of both punk and student radio (Casserley 2015), and the student stations' close identification with local and 'alternative' music (Bannister 2006: 95-6; Reilly and Farnsworth 2015: 13), is evidenced in long-term content levels of 30-40\% New Zealand-produced music (Mitchell 1997), and government funding based on that support (NZ on Air 2015). New Zealand music was a particular point of difference from commercial radio stations in the 1980s, which cited its low 'production values' compared with major international pop and rock acts as justification for limited airplay. (Shuker and Pickering, 1994, Mitchell, 1997: 98). Student radio has long been characterised by music demonstrating a range of production values, presented by predominantly volunteer on-air hosts with a variety of presentation styles (Casserley 2015). 
Radio U was renamed UFM after shifting to an FM broadcast frequency in 1986, and finally RDU in 1990, after financial crisis closed down UFM. It grew from a small short term radio club to a year-round broadcaster supported by a mix of government funding, limited advertising, and varying forms of subsidy from the UCSA. It has typically comprised a small number of paid full- and parttime staff and around one hundred volunteer DJs and newsreaders. In 2006 a new financial crisis prompted the UCSA to sell the business and its debts to the then-sales manager James Meharry and his partner Karyn South. Meharry and South continue to own and manage the station on its student-licensed frequency, and carried the burden of both maintaining broadcasts after the February 2011 earthquake, and creating a new future for the station.

This article examines how RDU was represented in the museum exhibition, in the context of the station's experiences after the February 2011 earthquake. It discusses the postquake period of the radio station's history as a background to the exhibition itself, as its survival plays a core role in the exhibition's story and form. Alternative Radio also located the longer history and ongoing cultural significance of the station within the broader context of national and regional heritage represented by the Canterbury Museum. With the intention of, in Meharry's words, 'making visible what is invisible' about radio broadcasting, the exhibition articulated RDU as a point of interconnection between the technical elements of broadcasting, the social and musical culture of station staff and volunteers, and the 'alternative' music scene of Christchurch and New Zealand.

The 'alternative' of the exhibition's title refers not specifically to a genre of music played on RDU, but the discursive construction of 'alternative' through particular practices of programming and presentation (Wall 2007). For RDU this may be most easily identified in the binary oppositions of student / commercial radio, local / international music, casual / polished presentation styles, and DIY / professional music production. 'Alternative' radio is 
constituted by values that valorise the exotic, the exciting, the substantial, the experimental, and the authentic (Wall, 2007: 40). These pervade all aspects of programming and presentation on student radio, of which the music may just be the most obvious.

Accordingly, ‘Alternative Radio' shared characteristics with exhibitions of popular music and local music scenes elsewhere. It drew on ad hoc archives of material curated by independent practitioners in the heritage framing of a museum. It did this, however, against the backdrop of a series of earthquakes that destroyed many of sites of personal and cultural memory. The exhibition presented historical stories and artefacts of RDU, but it also articulated the live practice of 'alternative' radio and its community.

\section{Music and Radio Heritage}

Like everything in Christchurch, the story of RDU and the Alternative Radio exhibition is entwined with the earthquakes' impact on the city's built environment, people, businesses, and music scene. The earthquake sequence began on September 4, 2010, with a 7.4 magnitude quake to the west of the city. Of the thousands of aftershocks that followed, the most severe was a 6.3 magnitude quake that occurred at $12: 51 \mathrm{pm}$ on 22 February 2011 . This was particularly destructive for its size (Wilkinson et.al., 2012), and its impact caused the collapse of two relatively new buildings and damaged many of the city's heritage buildings (Ingham and Griffith 2010, McFie 2013, Pickles 2016), causing the deaths of 185 people. The central city was cordoned off from the public until June 2013, as buildings were made safe or demolished. This caused massive disruption to businesses across the city (Hall et.al. 2016), including small independent radio stations that lost studios, transmission capability, and advertising income from the local businesses and music venues that were also disrupted 
or destroyed (Joyce, 2015). Christchurch has a strong history of local music production and performance (Mitchell 1997, Shepherd 2016), and the post-quake demolitions affected the 'emotional geography' of music in the city, disrupting links to the physical memory of venues and radio spaces, the details of which are 'salient features in the way in which audiences connect with their past and thus forge affective bonds in the present' (Bennett and Rogers 2016, 491). Roberts and Cohen identify former venues as music heritage memory sites that provide a 'performative space in which experiential memories can be rehearsed, acknowledged and re-embodied' (2013, 252, italics in original). After the widespread damage and demolitions in Christchurch some details of physical and collective memory associated with Christchurch venues and their broader city context have been preserved and recovered in post-quake publications (DESI301 Students 2016; Vavasour 2016; Shepherd 2016; Ballard et al. 2015; Cook 2014). As physical spaces of experiential music and radio memory no longer exist, other objects that anchor those memories (Leonard 2015,24) are imbued with greater resonance.

The heritage of popular music has been surveyed in writing on dedicated museums (Reising 2001; Kam 2004; Bruce 2008; Mortenssen and Madsen 2014), exhibitions in generalist museums (Leonard 2010, 2015), and a range of smaller scale 'DIY' spaces and archives (Baker and Huber 2013; Baker and Collins 2015; Collins 2015). Marian Leonard has described a range of music-focused exhibitions emerging from the personal practice of collecting popular music and culture artefacts (2007), addressing specific local music scenes in Liverpool (2010), Manchester, and Birmingham (2015). The latter exhibitions were developed by the Manchester District Music Archive (MDMA), and Birmingham's Home of Metal (HoM), local music 'activist archiving' organisations that were established to address the absence of local popular music scenes from the official sites of local heritage (Leonard 2015, 23). Like these organisations, RDU acted as an 'independent practitioner [...] working 
outside formal institutional structures, often balancing their endeavours with other work' (Leonard 2015, 19), by collaborating with an established museum to develop Alternative Radio from the station's own archive and the personal collections of fans.

The museum context inherently inscribed the objects of RDU as part of the "cultural heritage of New Zealanders", and particularly in relation to "the greater Canterbury region", in keeping with part of the Canterbury Museum's legislative obligation (Canterbury Museum Trust Board Act 1993). For objects of musical culture this kind of 'heritage' framing is often at odds with music's status as 'popular' or 'commercial' culture (Brandallero and Janssen 2013, 225). However, being put together by independent practitioners from archives kept by the community organisation, and its community members, the exhibition reflected a democratisation of memory and meaning-making in museum practice (Black 2011; Baker \& Huber 2013; Brandellero \& Janssen 2013; Roberts \& Cohen 2013).

The RDU exhibition at the Canterbury Museum is representative of more recent forms of 'bottom-up' heritage exhibition (Brandallero and Janssen 2013: 226), bestowing heritage status on the radio station itself, and also on the people who have contributed to its running over forty years, as nodes in broader networks of practice (Baker and Collins 2015, Leonard 2015) around music and radio in Christchurch. Artefacts in a museum 'construct, reflect and evoke particular histories' of musical culture (Leonard 2007: 2), activated as 'visitors bring their own narratives, histories and stores of knowledge which enable them to draw more complex understandings from the exhibits than might originally be envisioned by museum staff' (Leonard 2010: 178). In turn objects on display are 'incorporated into the extra-institutional memory of the museum-visitors', affirmed as significant by virtue of their presence in the museum (Crane 2000, 2). In an exhibition focused on a small local music scene, these objects elevated to museological significance will also be the subject of personal narratives, histories and stores of knowledge by visitors. Leonard (2010) identifies this 
process in the National Museums Liverpool The Beat Goes On exhibition, as the 'lived experience' of members of the city's music scene and its associated 'underground' values and status were included within the museum's broad narrative of Liverpool's social history (178). Personal location within that re-contextualised narrative is expressed by 'one well-known DJ [who] stared at an image of himself on the wall and declared "I can't believe that I am in the museum!"' (178). The museum exhibition translates individuals' experiences and 'collective memory into historical memory' (Leonard 2010, 178; also Keightley 2006; Bennett and Janssen 2015).

In exhibitions centred around musical cultures, the presence of music itself can play an important role in constructing, reflecting and evoking personal and collective histories and memory. Recorded, interactive, and even live musical content is often fully integrated in music museums and exhibitions (Bruce 2008; Reising 2001; Kam 2004; Leonard 2010, 173 4). Leonard also notes examples of museums using musical performance independently of popular music exhibitions as part of social inclusion strategies (2010). As a temporal medium music is deeply tied to memory retrieval and construction, and accordingly the development of self-identity (Frith 1996; DeNora 2006). Mortensen and Madsen argue that music plays an important role in evoking nostalgia in exhibition visitors, making it an 'efficient affective trigger,' for revisiting past times, and 're-enchanting' musical heritage (2014: 251). Music content can draw on the direct experience of museum visitors or trigger the 'mnemonic imagination' in others, a 'nostalgic longing for a past that has not been experienced first hand' (255), based on 'inherited memories' (Roberts and Cohen 2013, 252), built or imagined from the broader media around music.

Documented examples of musical cultures in museum exhibitions seem to overlook radio stations' roles in supporting music scenes. Shout Out! UK Pirate Radio in the 1980s at the ICA Potteries Museum and Art Gallery (2015) is a rare exception. Radio is an often 
Alternative Radio

invisible part of the networks in which objects of musical culture are located, however a radio station is likely to count as one of the 'wider social, cultural and economic processes surrounding the production and consumption' of music, musical history, and a particular canon of independent music (Roberts and Cohen, 2013: 243). Radio can certainly be located in the 'music assemblage' described by Born as 'a series or network of relations between musical sounds, human and other subjects, practices, performances, cosmologies, discourses and representations, technologies, spaces, and social relations' (2010, 87-8). Straw explicitly locates radio in the 'institutional infrastructures' of alternative rock music 'scenes', which include 'campus radio stations, independent record stores, and live performance tours' (1991, 376). Percival's analysis of commercial music radio finds that it acts as a 'mediator, as a cultural product, and as a cultural producer' in relation to the recording industry (Percival 2011,471 ), and on a smaller scale this is evident in local 'alternative' music, in which a radio station like RDU mediates the scene, produces forms of knowledge about that scene, and is produced by the activities of people within it.

Radio also has specific characteristics that lend themselves to new considerations for exhibition design and interaction. As Dolan observes in reference to the $\mathrm{BBC}$ written archives, 'The moment of transmission.... is a highly orchestrated production that is fully located within the complex relationships that play out between the $\mathrm{BBC}$, its personnel, its imagined audience and its empirical audience' (2003: 7). A student radio station is less highly orchestrated than the $\mathrm{BBC}$, but it is a production located in complex relationships, and material networks of objects and associated practices like those from which a pirate radio station is assembled (Fuller 2005). Radio is also performative, a transmission flow characterised by the intimate relationship between listener and broadcaster, bound together by the liveness of broadcast (Crisell 2012). Radio could further be considered a performative 
space like those discussed by Roberts and Cohen, in which experiential memories may attach to the sound of the radio itself and its physical studio spaces.

\section{Methodology}

This research emerged from a project documenting the experiences of Christchurch-based radio stations after the September 2010 and February 2011 earthquakes (Joyce, 2015). I interviewed James Meharry four times after the earthquakes. The first was in February 2012, when the station had resumed live broadcasting live only six months earlier. Follow up interviews in September 2012, and in 2015, traced the station's experience in the horse truck and move into more substantial studio space. The exhibition opened in March 2016, and in the weeks before it closed in August 2016, I interviewed Meharry, Rachel Morton, the former station manager who was employed by the Canterbury Museum to run public exhibition programmes, and Neil Philips, the Museum's Exhibitions Manager, who facilitated much of the discussion between the radio station, as independent practitioners, and the museum staff and exhibitions team. While the exhibition was open I carried out extended observations within the gallery, documenting the sounds and content of the space, and visitor interactions with it, in a version of the audience observations carried out by Leonard (2010). I also attended and observed at three of the gigs hosted in the exhibition space, and three live breakfast shows. Further primary material about the history of the station and the exhibition, came from radio documentaries produced by Radio New Zealand (2015), and RDU (2016), and the live to air exhibition broadcasts archived on the site Mixcloud.

\section{Christchurch earthquakes: The RDUnit}

The earthquakes destroyed RDU's university-based studio and much of central Christchurch, including many of the station's advertisers, local band venues and practice rooms, and the 
physical fabric of the city's 'alternative' culture. The earthquakes ruptured established structures (Pickles, 2016), and prompted a sense of urgency to salvage and preserve the material traces of the station's history.

The earthquake of 22 February 2011 cut power to the RDU offices and studio in the UCSA building, silenced the broadcast transmission, and prompted the evacuation of everyone in the building. Over the following weeks engineering checks confirmed that the building was no longer usable, and the station would be unable to resume broadcasting from it. RDU was well insured, so when it was possible to re-enter the building Meharry focused on retrieving personal effects and archival materials - documents, photographs, magnetic tape reels, and 7 inch records - rather than the more replaceable broadcast equipment.

In a city suffering ongoing aftershocks and the resulting widespread damage, uncertainty, and displaced businesses, it was not immediately possible to re-establish a functioning studio. However within a week of the earthquake, Meharry had plugged a laptop computer with a mobile modem directly into their transmitter in the Port Hills; 'literally just cut the cables and jacked in a laptop into the analogue transmission.' The laptop maintained the radio station from early March until July 2011, holding a selection of about 600 songs, which Meharry and the programme director could organise into playlists remotely. Within a few weeks, the breakfast show hosts were producing their show remotely by uploading voicebreaks to the laptop on the hill, and adding them in to the playlist. Meharry says it worked as a rough kind of live radio, 'if you really had a sharp ear to it, you would definitely hear it. But for all intents and purposes, breakfast ... basically operated as it was.' As the technology settled down other volunteers resumed their own radio shows. The station's production engineer Nik Coulter 'let hosts come around and actually mix their shows, with the voice-breaks, at his house, and then he would record them and upload them.' Meharry 
believes that doing radio shows again provided important continuity for both volunteers and audiences when everything else in the city was still so unsettled.

While the remote-access system enabled the station to broadcast in a basic form, for the ongoing practice of radio they required a space for people to do live radio shows, to gather, and to restore the broader business of a radio station. Meharry and South faced a rental property market with considerably increased costs, and they wanted to have more control over the future environment of the station than constricting rental leases would allow. The solution was a horse truck, a 1980 Mitsubishi Canter that was big enough to fit a small studio. Meharry designed and carried out most of the retrofit work himself, lining the interior with astroturf, fitting a dome window in the roof to accommodate taller DJs, and building and installing a full radio broadcast desk. It was launched with a party on 9 July 2011 . The new studio was initially mobile, enabling the station to participate more fully in events around the city, but it eventually settled into a semi-permanent home, parked in the garden of a house occupied by a youth social service organisation, which allowed greater certainty and security for the show hosts.

The 'RDUnit', as the horse truck studio was named, was the primary studio from July 2011 until May 2015, when the station moved into a more permanent built structure in the central city. Being untethered from its long term home on the suburban university campus, and the story of the RDUnit itself, increased the station's visibility so that it became a symbol of resilience and recovery in 2011 and 2012. In September 2012, Meharry observed

\footnotetext{
it's been humbling to see how people have been inspired by, you know, doing something [that...] seemed more pragmatic to me than risky or adventurous.... Some other people might just think about going and plugging into a room, but that's just not, I don't think that's the RDU way, that's not the RDU experience.
} 
The inspiration is captured by a profile in the national Sunday Star Times newspaper, which observed that Meharry and South 'could almost be pin-ups for the Christchurch rebuild young, hard-working, full of hope for the future' (Wall 2012). That sense of inspiration was evident in the staff as well as the broader public, and Meharry considers 'it protected the culture.' The station is now based in the 'Boxed Quarter' in Central Christchurch, a development of modular buildings planned after the February 2011 earthquake to house small business tenants, artists, and rehearsal studios. RDU will have a studio in the replacement UCSA building on campus, but the station's primary broadcast and business base is now permanently sited in the city centre. This move marks a significant break from the history of the station.

In the immediate aftermath of the earthquake, when the future location and form of the station was still unclear, the University of Canterbury's Macmillan Brown Archive accessioned the collection of RDU-related documents, recordings, and ephemera that Meharry rescued from the UCSA building - an institutional archive simply 'kept' rather than intentionally collected (Leonard 2007, 157-8). Students were engaged over the following years in documenting and cataloguing the material, creating a comprehensive record of the business and culture of the station. Meharry and South also used the documents to compile a detailed RDU history, including attempting to identify all of the people who have been involved as paid and volunteer staff, some of which was recounted on the station website as the 'History of U'. The documents tell a story not just about the radio station, but about the city it operates in, and the businesses, cultural organisations, events, musicians, and participants in its broader networks. In Christchurch all of these historical records carry the particular weight of representing a built past that is almost completely severed from the present, such that even the addresses of businesses and music venues are signifiers of a different place. 
As the immediate stresses of the earthquakes eased, Meharry and South began looking towards the fortieth anniversary in 2016 as a focus for bringing together the stories that emerged from the archive, and to mark the next, post-quake, phase of the station's history. Canterbury Museum were responsive to the idea of an exhibition; key staff were RDU listeners, and the museum saw this as a way to represent the post-quake story of a significant local organisation. The exhibition content was developed by the management and staff of RDU, acting as independent practitioners (Leonard 2015, 19), with guidance from the museum exhibition team for choosing successful content and exhibition elements. The exhibition looked back and also forwards, combining the forty-year history of the station, the RDUnit, and a specially-constructed broadcast studio that was later moved into the station's new permanent premises. There were two key issues to resolve in planning the exhibition. It needed to represent radio, a non-visual medium, in a visual and spatial way - not simply in images, but in objects and structures that would invite visitors to walk through the space. It also needed to represent a medium that was explicitly labelled as 'alternative' without establishing an opposition between the radio station and museum visitors.

\section{Making Alternative Radio 'accessible'}

For the museum, Alternative Radio was part of a strategy aimed at expanding audiences by appealing to specific target audiences as well as the broader community. RDU has involved hundreds of volunteers, staff members and musicians throughout a history that was closely interwoven with the cultural, musical, and student history of Christchurch. However, there was a risk that the exhibition could be seen as too exclusive. As Rachel Morton, station manager at the time the exhibition was developed, reflected, 'it was very easy for us as RDU to sort of think about the exhibition we would make for the RDU audience and for the people who love the station, and that would have been completely different' from the 
exhibition that was developed. The exhibition needed to tell a different story about the radio station and its community than the one RDU might tell itself - even though, as Meharry observed, that meant letting go of some entertainingly dramatic content.

Addressing both the target audience of RDU listeners and community, and the general visiting public meant identifying an accessible story and the objects to tell that story within a coherent visual display. One way of achieving this was to emphasise the station's location in broader cultural networks, and another was to identify objects around which stories about the radio station could coalesce - to represent radio, a non-visual, intrinsically ephemeral, medium in a museum context. By the time of the exhibition planning, the RDU organising team, as the exhibition's independent practitioners, were able to draw on a considerable amount of archival material documenting the station's people and its administrative, musical and social history. From this they drew up what Morton describes as 'the most enormous Excel [sheet] you have ever seen,' listing all the possible things that may be included, to which they attempted to apply museum staff advice to 'pare it back, pare it back, strip it out, whittle it down' (Morton). The resulting exhibition spreadsheet reads as an expanded version of the pirate radio elements itemised by Fuller $(2005,15)$. Inherent in the list is the possibility for each item to "open up into a matrix of immanent universes" (14). The exhibition document was pared back from a list of almost everything and everyone involved in RDU's history, to elements that could be brought together in a single space and time to tell a story.

Bringing the pieces together drew in a wide range of people from RDU's broader network. From the archive RDU staff identified, contacted and interviewed volunteers and staff. Through those interviews and advertisements on the radio station itself, people from around New Zealand loaned collections of t-shirts, posters, documents and ephemera, in a gesture of goodwill in keeping with the way a volunteer-based radio station works. These object loans demonstrate the role of personal collections as a signifier of musical knowledge 
and experience (Leonard 2007), and the 'ways in which enthusiasts play a role in how popular music and its culture are remembered' and contribute 'to the preservation of the artefacts of popular music's material past' (Baker and Collins 2015, 985). As the exhibition was developed oral histories of collectors added valuable knowledge about the production and reception of RDU and its music culture, and the scenes in which RDU, music, and its artefacts circulate and produce meaning.

As the objects and stories emerged the museum's exhibition design team developed ways to display materials that would fulfil different functions within the space. The exhibition resolved into themes of Broadcasting, Music, Events, and People, and the design and layout reflected that. A timeline of significant events in the station's history became the anchor for the exhibition narrative, creating an overall context for the objects and images in the rest of the exhibition hall. Inscribed on dividing walls, the timeline traced a pathway around the outside of the space, marking events, people, objects, and images along forty years of RDU's broadcast practice and its intersections with changing Christchurch music scenes, and the city's own built and social histories.

At the centre of the exhibition space, a stage to accommodate live performances constituted a space of musical possibility around which the exhibition was structured. Poster bollards opened out to form booths containing headphones and interactive iPad displays for listening to audio material, and could be moved from the centre to the edges of the room to create space for the audiences. A table facing the stage and backed by a wall of records and CDs became a sound and light mixing desk, while the wall itself served to baffle the sound between the stage and ceramics gallery space immediately opposite it. An RDU-decal'ed vintage Hillman Huskie, also useful for attracting visitors more interested in cars than RDU itself, could be driven out of the space for performances. 
Further around the room exhibits included a graphic representation of specialist radio shows over the years, displays of promotional T-shirts, records, posters, technical equipment, models of promotional vehicles, and representations of future plans. Screens played documentaries about RDU events and history. A slideshow projected above the stage displayed photographs and quotes from station volunteers and staff, reflecting on the meanings of the station in the lives of its people. As the stage itself was largely empty on weekdays, the screen performatively centred the individuals who have sustained the station from behind the microphones. There and throughout the exhibition, images and names of station staff and volunteers located individual experience in the collective memory of the radio station (van Dijk 2004, 262; Keightley 2006, 154), and the cultural memory actively defined by their presence in the museum (Black 2011). The Liverpool DJ's exclamation of recognition, 'I can’t believe I am in a museum!' (Leonard 2010, 178) was echoed by visitors finding themselves elevated into the institution's historical memory.

Other objects throughout the exhibition also materialised individual, collective and cultural memory of the interconnections between radio, music, and the city within which the local music scene developed. Posters documented bands, events, and venues long gone. Some represented a musical scene on the edges of international recognition with the Flying Nun record label (DESI301 2016, Shepherd 2016). Others articulated the city's location in international touring networks for musicians and DJs. Like many of the timeline photographs, the posters represented elements of Christchurch's lost heritage, referencing and documenting spaces and buildings destroyed in the earthquakes and the city's subsequent reconfiguring. Many venues had ceased to function as such long before 2011, but the earthquakes finally erased the remaining buildings and their built context (e.g. Vavasour 2016), in a violent and sudden version of the redevelopment that affects all local music scenes. Posters and photographs referencing lost venues became 'archival remains' of the material culture of the 
city's pre-quake musical practice (Leonard 2015, 24), connecting past, present, and 'an emotive attachment to local spaces' (Bennett and Rogers 2016, 492). They created a performative space for rehearsing and acknowledging memory, either first-hand or 'inherited' (Roberts and Cohen 2013, 252). This form of nostalgia was evoked by Morton, who after working on the exhibition materials and collected memories, expressed a retrospective sense of 'massive FOMO', Fear Of Missing Out, on the 1990s rave scene that flourished long before her arrival in the city.

Record and CD covers on display represented more concrete music objects from the RDU collection and Meharry's more recent archival practice of creating lathe-cut records for local bands. The wall of album covers opened spaces for personal narratives, histories, and knowledges tied to self-identity and visitors' own actual, remembered, or imagined collections. Many of these were marked with slogans identifying 'Radio U', 'UFM', or 'RDU' and admonishments such as 'Do not steal', anchoring them not simply as records signifying a particular genre or period of music, but the examples of that music that were actually played on the radio. Another wall of record covers represented 7" records from the station's future-focused archive, lathe cut by Meharry. Meharry's lathe cutting enterprise reflects a personal attachment to the record as object, grounded in his own experience as a Drum and Bass DJ, and a sense of the historicisation of music.

Although the posters and records related to music performance, production and consumption in Christchurch more broadly, the exhibition had to tell those stories in the context of radio, making visible the usually invisible processes of broadcasting. For some museum visitors there were many objects of direct experiential memory in the old radio equipment on display, including the original Radio U broadcast desk from 1976, and a rack of one-track looped cartridges still labelled with the advertisements, station ids and songs they last carried before the station shifted to a computerised playlist in the late 1990s. The 
biggest physical representation of radio was the broadcast studio constructed to be dismantled and shifted into the station's next location. It was used for broadcasts, workshops, and sound mixing, and signified the next stage in the station's history. However the studio also integrated particularly resonant memory objects that were part of the fabric of the station before the earthquake: the original broadcast studio windows bearing decades of stickers representing bands, record labels, RDU itself, and other radio stations. These were the most concrete remnants of the old studios, evoking an emotional attachment to the radio station as a place of music memory. Meharry characterises the stickers as a genealogy of alternative radio and local music, so that each sticker-clad window is a 'window into the past,' in which a sticker represents 'its own little time zone' alongside the times and places represents by the other stickers.

\section{Radio, Music and community}

While the exhibition was visually constructed from the objects and representations of RDU's social history and community, music played an important role in tying all of the elements together. Recorded music content took several forms in the space during the day, and live music attracted different kinds of audiences in the evenings. The exhibition structure was determined by the need to accommodate gigs, live broadcasts, and live to air performances. Morton moved from her role at RDU to become Public Programmes Manager for the exhibition, so that she could coordinate the live music content more effectively between the museum and the radio station.

Several forms of recorded music gave the exhibition space a sense of activity, as ambient audio content accompanying screen-based documentaries, and recordings for listening via headphones and an app. The most present musical element was an audio track of 100 songs that were representative of RDU's content over forty years. As Morton observes, the exhibition felt 'static' when the audio track was silent: 
you need music to listen to when you're looking at an empty stage, you need music to listen to when you're looking at gig posters. You need that when you're looking at a music wall with vinyl and CDs and you've got music playing and you might even hear a song by an artist that you're looking at.

This reflects criticism that silent music exhibitions are like "mausoleums"... becalmed [and] opposed to the vital energies of pop and rock' (Reynolds in Mortensen and Madsen 2014, 251). The same songs were available for listening via headphones on a jukebox in one of the poster-bollard listening booths. Simply playing the radio station itself in the space for musical ambience was decided against because of both the inexperience of many daytime DJs and music that may not be considered museum friendly - because of 'cursing' for example. For RDU that would have been perhaps more authentic, in its discursive construction of 'alternative radio' in practice and programming (Wall 2012), but it illustrates the tension between being 'alternative' and accessible enough for everyday music visitors. Instead of the radio station itself, the playlist, dubbed 'Heard it Here First' comprised songs that represented the sound of RDU over the decades. It included a mixture of international and local music by performers like The Fall, The Gordons, Public Enemy, The Orb, Straitjacket Fits, Sonic Youth, Aphex Twin, The Clean, Ladi 6, Major Lazer, MIA, and Marlon Williams.

\section{Performance}

Recorded music was a reasonable compromise for daily museum ambience, but the most important representation of RDU's broader community connections was in the performance of live music and radio itself. Accommodating live music and radio events brought new objects into the exhibition space, and new forms of activity, in preparation, performance, and pack down. 
In preparation for events, the stage area became a site for exhibiting the equipment of live music and broadcast radio. Drum kits, amplifiers, monitor speakers, microphones, turntables, and synthesisers were arranged in combinations reflecting a diversity of local music practices. For a live breakfast show the stage became a broadcast space displaying the materiality of radio (Fuller 2005) - an inward-focused site with desk, microphones, headphones, computers, and cables, set up for a potential physical audience. Live-to-air musical performances combined the two: the stage set up for a gig but with the technical focus of broadcast sound engineering, performing both musical content and the activity of radio production. Occurring on weekends, these events created differing weekend and weekday senses of space, which was most evident when observing the exhibition on a Friday afternoon, as technicians began bringing equipment in for the following day. Amplifiers and flight cases stacked around the stage space were refigured from objects of music performance to exhibition pieces, as were the performers, technicians and radio hosts themselves (RDU 2016).

Four major gigs were held on weekend nights during the exhibition run, featuring musicians who were closely associated with the station through their music, and in some cases as volunteers and staff members. Each gig had a theme that articulated a core part of RDU's musical identity and the local music scenes with which it is connected: 'alt country', 'indie', hop hop, and electronica. Potential damage to the ceramics collection in the neighbouring gallery space was mitigated by both the earthquake protection measures that reduced the impact of sound vibrations, and careful testing of volume levels. The gigs articulated RDU's connection to the local music scene in an active, contemporary manner, ensuring that the museum setting did not position the station as a form of static heritage.

While the live gigs carried the highest profile of the musical events, the live breakfast shows most clearly performed the radio station's visibility as a carrier of music and a focus of 
community connection. Five live broadcasts were hosted by breakfast DJs from the 1980 s to 2016. These broadcasts were performed live on stage in the exhibition space, articulating radio as both content and performance. The hosts played music of their broadcast period, and reflected on the experiences of making radio and subsequent changes in their own lives, in the city, RDU, and music itself. Interviews and guests added multiple narratives of past versions of the radio and the city. Although there is a history of live public performance in radio, 'doing a radio show' is usually an experience of talking to an unseen, imagined audience (Douglas, 2004). Doing that same radio show on a stage in a large public space creates a more explicit performativity: people sitting at a table wearing headphones and talking thoughtfully into microphones, but with staging that reveals the performance and artefacts usually hidden by the act of transmission.

These breakfast shows attracted a live audience as people explored the exhibition and sat in front of the stage to observe the performance of radio. The acoustic space of the large exhibition gallery also became part of the broadcast, so that it was possible listening from home to hear the museum through the incidental background sounds (Chignell 2009, 91) in tangible contrast to the acoustic silence of an insulated broadcast studio. Echoes and resonance made the museum itself part of live radio, along with strains of video soundtracks from the exhibition and the variable sound textures of visitors. Applause and laughter created a convivial studio audience ambience, while sounds of other museum visitors passing through the exhibition space, transmitted the experience and space of the live museum along with the broadcast.

\section{Conclusion: Networks, people, broadcasting}

Alternative Radio foregrounded the interrelationship of local music and a student radio station in a small city in New Zealand. As a singular exhibition it tells a specific history, but 
it provides a model for making visible what is invisible about radio in museum form. The exhibition demonstrated the materiality and the practice of 'alternative' radio, and also the local music scene in which the radio station is embedded. In Christchurch this history is particularly inflected with the 'rupture' of the earthquakes and demolitions (Pickles 2016), in both the built environment and in collective and historical memory. This has driven understanding of the need to archive and articulate connections between the past, present and future. The exhibition was a compilation of ' $k e p t$ ' institutional archives and the vernacular knowledge of enthusiasts, brought together in the institution by independent practitioners with the guidance of museum staff. By placing the radio station and its networks into the museum context the exhibition connected the individual memories of participants, gathered through oral histories and the exhibition research, with collective memories both experiential and inherited, evoked by the posters, records and other objects, and the historical memory carried by the museum itself. Placement in the museum, among the objects and displays that ground the city's colonial history positions the radio station into that heritage.

A radio station is not simply a vehicle for recorded music, but part of a broader cultural scene. It is a node in a network of staff, volunteers, musicians, promoters, technical crew, venue workers, poster designers, printers, billstickers, advertisers, sponsors, and the active listening audience itself. The live gigs and broadcasts made this explicit, and emphasised that RDU's role in this creative network is not an object of heritage, but a core part of the station's ongoing practice and identity.

\section{References}

Baker, Sarah, and Alison Huber. 2013. "Notes Towards a Typology Of The DIY Institution: Identifying Do-It-Yourself Places Of Popular Music Preservation.” European Journal of Cultural Studies 16 (5): 513-530. 
Baker, Sarah and Jez Collins. 2015. "Sustaining Popular Music's Material Culture in Community Archives and Museums." International Journal of Heritage Studies 21 (10): 983-996.

Ballard, Susan, Tracey Benson, Robert Carter, Tim Corballis, Zita Joyce, Helen Moore, Julian Priest, Vicki Smith. 2015. A Transitional Imaginary: Space, Network and Memory in Christchurch. Christchurch: Harvest Press

Bannister, Matthew. 2006. White boys, white noise: Masculinities and 1980s indie guitar rock. Aldershot: Ashgate Publishing.

Bennett, Andy, and Ian Rogers. 2016. "In the Scattered Fields of Memory: Unofficial Live Music Venues, Intangible Heritage, and The Recreation of the Musical Past.” Space and Culture 19 (4): 490-501.

Bennett, Andy and Susanne Janssen. 2015. "Popular Music, Cultural Memory, and Heritage." Popular Music and Society 39 (1): 1-7.

Black, Graham. 2011. "Museums, Memory and History." Cultural and Social History 8 (3): $415-427$

Born, Georgina. 2010. "Listening, Mediation, Event: Anthropological and Sociological Perspectives.” Journal of the Royal Musical Association 135 (S1): 79-89.

Brandellero, Amanda and Susanne Janssen. 2013. "Popular Music as Cultural Heritage: Scoping Out the Field of Practice.” International Journal of Heritage Studies 20 (3): 224-240.

Bruce, Chris. 2008. "Spectacle and Democracy: Experience Music Project as a PostMuseum." In New Museum Theory and Practice: An Introduction, edited by Janet Marstine, 129-51. Chichester: Wiley-Blackwell.

Canterbury Museum Trust Board Act 1993. Accessed 26 July 2017. http://www.legislation.govt.nz/act/local/1993/0004/latest/whole.html\#DLM81358

Casserley, Paul. 2015. Radio Punks - The Student Radio Story. Documentary aired Prime TV, New Zealand, 16 August 2015.

Chignell, Hugh. 2009. Key Concepts in Radio Studies. London: Sage.

Churton, Wade. 2003. Alternative music in New Zealand, 1981-2001: Definitions, comparisons and history. MA Thesis, University of Canterbury, New Zealand. 
Collins, Jez. 2015. "Doing-It-Together Public History-Making and Activist Archiving In Online Popular Music Community Archives.” In Preserving Popular Music Heritage: Do-It-Yourself, Do-It-Together, edited by Sarah Baker, 77-90. London: Routledge.

Cook, David. 2014. Meet Me in the Square: Christchurch 1983-1987. Christchurch: Christchurch Art Gallery Te Puna O Waiwhetu.

Crane, Susan A. 2000. "Introduction: Of Museums and Memory." In Museums and Memory, edited by Susan A. Crane, 1-13. Stanford: Stanford University Press.

Crisell, Andrew. 2012. Liveness and Recording in the Media. Houndmills: Palsgrave

DeNora, Tia. 2006. “Music and Self-Identity.” In The Popular Music Studies Reader, edited by Andy Bennett, Barry Shank, and Jason Toynbee, 141-147. Abindgon: Routledge.

DESI301 Students. 2016. Un-Stuck: Band Posters from the Christchurch City Libraries Archives (1980-89). Christchurch: Ilam Press.

Dolan, Josephine. 2003. "The Voice That Cannot Be Heard: Radio/Broadcasting and 'The Archive'." The Radio Journal 1 (1): 63-72.

Douglas, Susan. 2004. Listening in: Radio and the American Imagination. Minneapolis: University of Minnesota Press.

Frith, Simon. 1996. "Music and Identity." In Questions of Cultural Identity, edited by Stuart Hall and Paul du Gay, 108-127. London: Sage.

Fuller, Mathew. 2005. "The R, the A, the D, the I, the O: The Media Ecology of Pirate Radio.” In Media Ecologies: Materialist Energies in Art and Technoculture, 13-53. Cambridge, Mass.: MIT Press

Hall, C. Michael, Sanna Malinen, Rob Vosslamber, and Russell Wordsworth. 2016. "Introducion: The Business, Organisational and Destination Impacts of Natural Disasters - the Christchurch Earthquakes 2010-2011.” In The Business, Organisational and Destination Impacts of Natural Disasters - the Christchurch Earthquakes 2010-2011, 3-20. Abingdon: Routledge.

ICA The Potteries Museum and Art Gallery. 2015. Shout Out! UK Pirate Radio in the 1980s: Educator's Resource Pack. Accessed 19 July 2016. https://www.ica.org.uk/sites/default/files/downloads/ICA\%20Educator's\%20Resourc e\%20Pack\%20Shout\%20Out.pdf 
Ingham, Jason and Michael Griffith. 2010. "Performance of Unreinforced Masonry Buildings During the 2010 Darfield (Christchurch, NZ) Earthquake.” Australian Journal of Structural Engineering 11 (3): 207-223.

Joyce, Zita. 2015. "RadioQuake: Getting Back 'On Air' After the Christchurch Earthquakes." Radio Journal: International Studies in Broadcast and Audio Media 13 (1): 57-73

Kam, Jacqueline. 2004. "Success in Failure: The National Centre for Popular Music." Prometheus 22 (2): 169-187.

Keightley, E. 2006. "For The Record: Popular Music and Photography as Technologies of Memory.” European Journal of Cultural Studies 9 (2): 149-165.

Leonard, Marion. 2007. "Constructing Histories Through Material Culture: Popular Music, Museums and Collecting." Popular Music History 2 (2): 147-167.

Leonard, Marion. 2010. "Exhibiting Popular Music: Museum Audiences, Inclusion and Social History." Journal of New Music Research 39 (2): 171-181.

Leonard, Marion. 2015. "The Shaping of Heritage Collaborations Between Independent Popular Music Heritage Practitioners and the Museum Sector.” In Preserving Popular Music Heritage: Do-it- yourself, Do-it-together, edited by Sarah Baker, 19-30. New York: Routledge.

McFie, Rebecca. 2013 "Rush to Ruin: Christchurch's Heritage Buildings are a Must Keep." In Report from Christchurch, 68-76. Wellington: Bridget Williams Books.

Mitchell, T. (1997). Flat city sounds. Popular Music and Society, 21(3), 83-105.

Mortensen, Christian Hviid and Jacob Westergaard Madsen. 2014. "The Sound of Yesteryear on Display: A Rethinking of Nostalgia as a Strategy for Exhibiting Pop/Rock Heritage.” International Journal of Heritage Studies 21 (3): 250-263.

NZ on Air. 2015. NZ On Air backs New Zealand radio. Accessed 24 July 2017. http://www.mch.govt.nz/news-events/news/nz-air-backs-new-zealand-radio

Pickles, Katie. 2016. Christchurch Ruptures. Wellington: Bridget Williams Books.

Percival, J. Mark. 2011. "Music Radio and The Record Industry: Songs, Sounds, and Power." Popular Music and Society 34 (4): 455-473.

RDU. 2016. \#RDU40 Alternative Radio: A Deeper Look. Accessed 29 November 2016. https:/www.mixcloud.com/RDU/playlists/rdu40-alternative-radio-a-deeper-look/ 
Reilly, Brendan, and John Farnsworth. 2015. Going commercial: Navigating student radio in a deregulated media marketplace. Interactions: Studies in Communication \& Culture 6 (1). Pp 9-27.

Reising, Russell. 2001. "The Secret Lives of Objects; The Secret Stories of Rock and Roll: Cleveland's Rock and Roll Hall of Fame and Museum and Seattle's Experience Music Project." American Quarterly 53 (3): 489-510.

RNZ. 2015. A History of Student Radio: Episode Two. Accessed 30 November 2016. http://www.radionz.co.nz/national/programmes/a-history-of-student-radio/20150103

Roberts, Les and Sara Cohen. 2013. "Unauthorising Popular Music Heritage: Outline of a Critical Framework.” International Journal of Heritage Studies 20 (3): 241-261.

Shepherd, Roger. 2016. In Love with These Times: My Life with Flying Nun Records. Auckland: Harper Collins.

Shuker, Roy, and Michael Pickering. 1994. "Kiwi Rock: Popular Music and Cultural Identity in New Zealand." Popular Music 13(3): 261-78.

Straw, Will. 1991. "Systems of Articulation, Logics of Change: Communities and Scenes in Popular Music.” Cultural Studies 5 (3): 361-375.

van Dijck, Jose. 2004. "Mediated Memories: Personal Cultural Memory as Object of Cultural Analysis." Continuum 18 (2): 261-277.

Vavasour, Kris. 2016. More Than a Band Aid: How the Use of Popular Music Helped a City Recover after Disaster. Unpublished MA Thesis, University of Canterbury New Zealand.

Wall, Tim. 2007. "Finding an alternative: Music programming in US college radio." The Radio Journal - International Studies in Broadcast and Audio Media, 5(1): 35-54

Wall, Tony. 2012. "Staying Live.” Sunday Star Times, C, February 19

Waterton, E., \& Watson, S. 2013. "Framing theory: Towards a critical imagination in heritage studies." International Journal of Heritage Studies, 19(6)

Wilkinson, Sean, Damian Grant, Elizabeth Williams, Sara Paganoni, Stuart Fraser, David Boon, Anna Mason, and Matthew Free. 2012. “Observations and Implications of Damage from the Magnitude Mw 6.3 Christchurch, New Zealand Earthquake of 22 February 2011.” Bulletin of Earthquake Engineering 11 (1): 107-140. 
Wyse, N.A. 1977. Letter to the Broadcasting Tribunal. Accessed 24 July 2017.

https://www.dropbox.com/s/n5qclyh9lcn1 zfn/Pink\%208\%20Letter\%20for\%20licence \%20application\%20for\%201978.pdf?dl=0 